\title{
Poesia em vídeo
}

\author{
Acir Dias ${ }^{1}$ \\ Laura Coutinho ${ }^{2}$ \\ Rosalia de Angelo Scorsi ${ }^{3}$
}

\section{RESUMO}

Este artigo é o relato escrito de uma experiência de produção audiovisual desenvolvida no Laboratório de Estudos Audiovisuais - OLHO, da Faculdade de Educação da UNICAMP. Aborda o processo de criação de um vídeo poema concebido com a intenção de fundir as linguagens poéticas das imagens, dos sons e das palavras. O resultado final, PAISAGEM EM AZUL, um vídeo de 4 min. 12 Seg., reúne um poema - fragmento de Mário Faustino, imagens por ele inspiradas e a música instrumental do Grupo UAKTI.

A cantina da Faculdade e Educação é um lugar de encontro de alunos/ professores antes, depois ou nos intervalos de aulas. Ali, nos intervalos do Grupo de Pesquisa Olho (Laboratório de Estudos Audiovisuais), a idéia de produzirmos um vídeo-poema começou a tomar forma concreta. Queríamos experimentar, com uma câmera na mão, expressarmo-nos em linguagem da poesia. Queríamos traduzir uma estética em outra - o poema escrito em vídeo-poema. O impulso vinha de nossas experiências com a linguagem/ imagens do cinema. Neste trabalho com poesia, foi decisiva a influência do texto de Pasolini: Cinema de Poesia $^{4}$. Esse texto nos diz da qualidade onírica profunda do cinema e da possibilidade de expressar o poético, no

\footnotetext{
${ }_{2}^{1}$ Acir Dias é mestrando na Faculdade de Educação - Unicamp.

Laura Coutinho é professora da Universidade de Brasília e doutoranda na Faculdade de Educação - Unicamp.

${ }^{3}$ Rosalia de Angelo Scorsi é doutoranda na Faculdade de Educação - Unicamp.

${ }^{4}$ P. P. Pasolini, Empirismo Hereje, Lisboa, Assírio e Alvim, Coop. Edit. e Livreira, 1982.

Olhar de professor, Ponta Grossa, 2 (2):125-133, nov. 1999.
} 
cinema - poesia que se liberta da prosa comunicativa narrativa com que o cinema funda sua tradição. Os exemplos dessas experiências vinham de Antonioni, Bertolucci, Godard e, no Brasil, Glauber Rocha. Interrogando se é possível ao cinema a língua da poesia, o autor refere-se à câmera Subjetiva Indireta Livre: um estilo sensível de atuar com a câmera e os recursos audiovisuais, em que inspiração e técnica se consubstanciam em uma poética cinematográfica. A câmera Subjetiva Indireta Livre, no cinema, corresponderia ao Discurso Indireto Livre, na literatura. Trata-se de uma liberdade anormal de usar a câmera que se manifesta numa câmera quase escandalosa em sua insistência de um modo de enquadramento dos planos e dos ritmos da montagem, desaguando em uma duração específica de planos e ritmos, desejantes de expressar a alma do que é focado. A câmera foca os objetos da realidade, acariciandoos em um íntimo afeto entre os participantes do ato: homem-câmera-objeto.

O ponto de partida foi um poema. Talvez pudéssemos, inspirados nas imagens poéticas do texto escrito, criar o poético em linguagem da câmera. Imbuídos dessas idéias, decidimos traduzir em imagens audiovisuais o poema-fragmento de Mário Faustino Juventude, que pertence à série de po- emas curtos, sem títulos, produzidos entre 1959 a 1962. Esses poemas curtos correspondem ao desejo do poeta de criar "o longo poema", composto desses pequenos poemas heterogêneos na forma e nos temas, chamados poemas-fragmentos. Os poemas-fragmentos iniciam e terminam com reticências, como se esses três pontos iniciais e finais fossem eles também versos. Os fragmentos poéticos, então, tornam-se um poema sem fim, pronto à continuidade. Trata-se de uma forma de composição poética ocasional e circunstancial, anotações esparsas, estruturadas e reconstruídas depois. Composição muito próxima do fazer cinematográfico em que os versos são criados como se fossem takes. Ou, pensando nas palavras de Jean Epstein, um poema saturado da estética do cinema, em que vemos metáforas, mostrando as coisas e seres em proximidade, sugestiva e sensualmente, na sucessão e no movimento rápido, fiel ao fervilhar da vida. ${ }^{5}$

O poema Juventude, então, pareceu-nos muito adequado para ser dito em imagens de vídeo, dado seu forte apelo sensorial, musical e visual. Eis o poema ${ }^{6}$ :

\footnotetext{
${ }^{5}$ Ver a respeito, Jean Epstein, "O Cinema e as Letras Modernas", em A Experiência do Cinema, (org. Ismail Xavier), RJ, Edições Graal: Embrafilme, 1983.

${ }^{6}$ Esse poema fragmento consta do livro de poemas de Mário Faustino, O Homem e sua Hora, RJ, Ed.Civilização Brasileira S.A., 1966.
} 
$\cdots$

Juventude -

a jusante a maré entrega tudo -

maravilha do vento soprando sobre a maravilha de estar vivo e capaz de sentir maravilhas no vento -

amar a ilha, amar o vento, amar o sopro,

o rasto -

maravilha de estar ensimesmado

(a maravilha: vivo!)

tragado pelo vento, assinalado

nos pélagos do vento, recomposto

nos pósteros do tempo, assassinado

na pletora do vento -

maravilha de ser capaz,

maravilha de estar a postos,

maravilha de em paz sentir

maravilhas no vento

e apascentar o vento,

encapelado vento -

mar à vista da ilha,

eternidade à vista

do tempo -

tempo: sempre o sopro

etéreo sobre os pagos, sobre as régias do vento,

do montuoso vento -

e a terna idade amarga - juventude -

extase ao vivo, ergue-se o vento lívido,

vento salgado, paz de sentinela

maravilhada à vista

de si mesma nas algas

do tumultuoso vento,

de seus restos na mágoa

do tumulário tempo,

de seu pranto nas águas do mar justo -

maravilha de estar assimilado

pelo vento repleto e pelo mar completo

- juventude -

- a montante a maré apaga tudo -

...
Na primeira reunião para andar o trabalho, decidimos fazer um exercício de imaginar com que formas animaríamos o poema em imagens sonoras e visuais. Isto traríamos escrito na reunião seguinte, em que concordamos com uma IDÉIA geral a ser perseguida: "Criar um conjunto de imagens que expressem os temas, o movimento e a força poética do texto escrito. Expressar em vídeo a alma do poema. O texto escrito fará parte do conjunto de imagens. O poema, muito próximo ao canto, repleto de assonâncias, aliterações, repetições, pede um movimento ondulatório que reflita o encantamento amoroso da juventude. Sentimento lutuoso também, pois a juventude, terna idade amarga, embora no fluxo da eternidade, ao recortar-se no ciclo temporal do sujeito que canta, é efemeridade e passagem."

Definida a idéia geral, o passo seguinte foi delinear uma seqüência de imagens, um roteiro, para que pudéssemos iniciar a captação de imagens. Na Supervisão de Criação, contamos com os pareceres do prof. Milton José de Almeida (coordenador do laboratório), que nos ajudou a definir uma harmonia estética em que som, ritmo, imagem, cromo e palavra se afinassem.

Para pensar o poema-vídeo, teríamos de esquecer as imagens escritas, mantendo em nossa subjetividade a pulsão estética que o poema provoca, e daí gerar as imagens, agora, em vídeo-linguagem. A questão era: como conseguir semelhante efeito 
estético, do leitor do poema, ao espectador de vídeo? Não podíamos ceder ao impulso de construir uma prosa narrativa, que faz parte da essência da representação fílmica, pois tínhamos à frente uma composição abstrata, conceitual e metafórica, que deveria ser mantida na transposição.

Diversas perguntas precisavam ser respondidas: quanto tempo duraria o vídeo? Qual seria sua imagem nuclear? Que som colaríamos a essas imagens? De que modo entraria a palavra escrita? Isolada? Colada sobre imagens? Essas e outras perguntas tinham de ser respondidas com os recursos técnicos oferecidos pela Faculdade de Educação e/ou pelo Centro de Comunicação da Unicamp: um tripé, uma câmera semi-profissional, um operador de câmera. Sem qualquer verba, tínhamos de optar por uma forma simples e econômica.

Muitas vezes, lemos o poema para nos impregnar de seus sons, ritmos, metáforas. Em silêncio. Em voz alta. Ouvindo a leitura do outro...

\section{Plano a Plano}

... Verso a verso a poesia de Mário Faustino era nosso ponto de partida. Era ela que deveria guiar o nosso olhar, na busca das imagens, como um dedo apontando:

maravilha do vento soprando sobre a maravilha de estar vivo e capaz de sentir maravilhas no vento
Seria preciso que o nosso olhar enquadrasse um vento soprando, um tempo, juventude. E o vento tem a mesma forma invisível do tempo. $\mathrm{O}$ que é visível são as marcas, os rastos que ficam nas coisas por onde o tempo e o vento passam, jamais eles mesmos. E por onde passam movimentam e transformam as coisas.

Como registrar em imagens e sons alguma coisa feita de uma matéria que é menos para ser vista do que para ser pressentida? Se assim também é a poesia? Feita de palavras que, impressas na página em branco do livro, são marcas visíveis e sugerem mais do que afirmam impressões e sentimentos.

As palavras eram imprescindíveis e entrariam na imagem de alguma forma. Primeiro tentamos inscrevê-las, à tinta, no dorso do corpo jovem. Depois, pensamos que poderiam aparecer impressas no próprio livro ou numa página em branco sobre uma coluna posta na relva. No final, as palavras entraram soltas, como que sopradas para dentro da tela. Verso a verso, o texto escrito, corre na parte inferior do quadro, sobre as imagens, em sentido inverso à varredura da leitura ocidental: da direita para a esquerda. A reticência inicial corre isolada, como se fosse um primeiro verso. Como último verso, corre a reticência final. Esta escolha não permite que o espectador/leitor capte tranqüilamente o texto escrito. Ao contrário, a leitura do texto é problemática, truncada, aos pedaços. O que 
provoca a fixação de algumas palavras na memória, devido a insistência com que aparecem:

juventude, maré, mar, amar, maravilha, vento.

A associação dessa leitura angustiante com as imagens e sons produzidos no vídeo é que compõe o significado que cada espectador formula.

A busca das imagens, a princípio, nos levara ao vento nas folhas, à chuva caindo e formando círculos concêntricos em pequenas poças, ao vento passando entre galhos refletidos na água. Imagens captadas, ao acaso, na rua, no fundo do quintal, da janela de um apartamento. Mas não era ainda esse o movimento que pressentíamos na tela. Havia também, na poesia, algo de estático em tensão. Então, procuramos objetos, cerâmicas, instrumentos de percussão, folhas secas desgarradas e tecidos de várias texturas que pudessem compor nossa outra alegoria de imagens e sons. Desistimos também desse cenário criado dentro de casa. Com os tecidos chegamos aos vestidos femininos que, pela textura e formas desenhadas, puderam, suspensos no ar, realizar movimentos: um cabide, suspenso por uma longa vara, flutua no ar, contra o céu azul - ora uma brisa leve ondula suas sedas, em contra-plongée, ora a silhueta da parte superior do vestido, onde os seios se abrigariam, fixa-se por instantes na tela.
A paisagem sugerida na poesia envolvia a juventude com o movimento de ir e vir das marés. E os sinais visíveis do tempo e do vento estariam no corpo. Seria, então, o próprio corpo, o rasto. E um corpo masculino se fez paisagem contra o céu, em vários tons de azul, oscilando com dia no seu transcorrer. Às vezes, claro quase cinza nas manhãs, às vezes, forte e profundo ao meiodia. Encontramos, nessa tensão de luz e de sombra, o contraste que buscávamos com as imagens das partes captadas do corpo assemelhando-se a paisagens geográficas. E, além da luz e da sombra, havia a tensão do movimento quase imperceptível do corpo estático desejando parar o tempo e enquadrar-se - paisagem - na tela. Plano a plano, foi o corpo que delimitou o contraste recortando o azul. O nosso contra-luz era um contra azul. Quase roxo, às vezes cinza, anil. O corpo talhado pela câmera recorta o céu, quebrando o retângulo que a rigidez do $4 \mathrm{X} 3$ fixa na tela. Por ali, nos recortes, foi possível encontrar o verso, a forma, a cor, o ritmo. Ritmo das ondas, da respiração, do tempo.

Era essa a paisagem que a poesia de Mário Faustino nos soprava. Eram aqueles os planos que a câmera, desejando-se subjetiva e livre, nos revelara. Plano a plano, era preciso apreender o corpo, o tecido feito vestido, a paisagem para compor a linguagem audiovisual que se faria poesia. Recortar imagens e tempo. A 


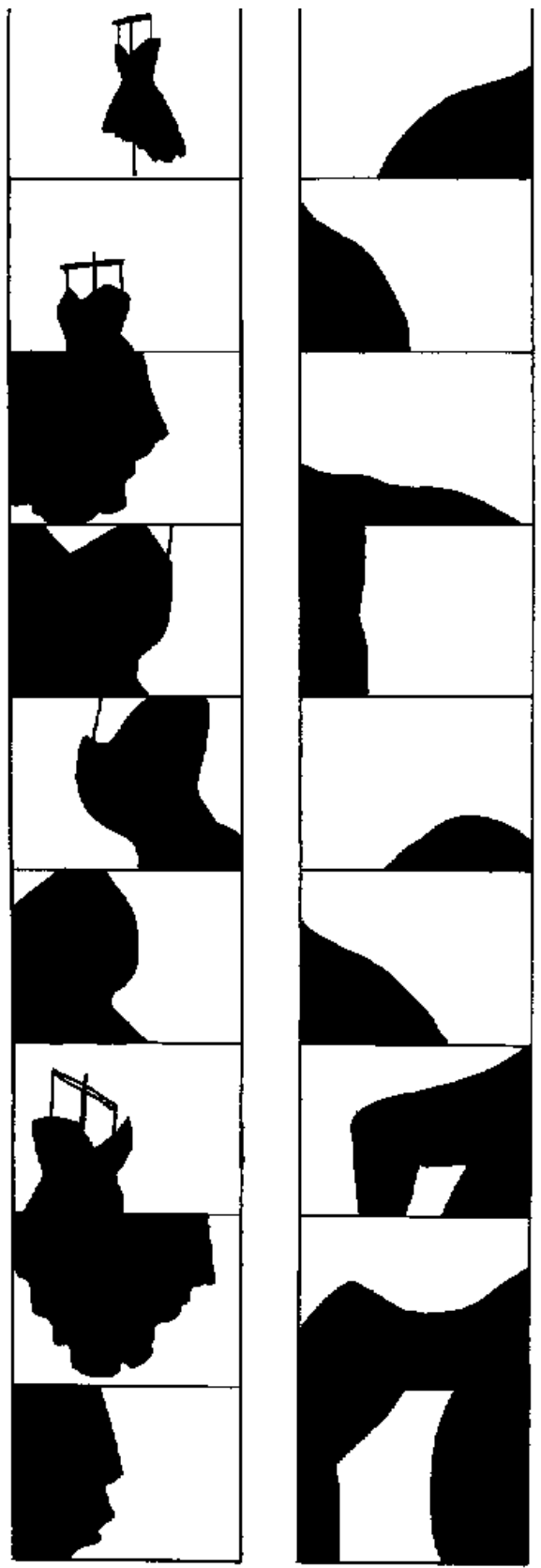

imagem impressionada na fita só se revela na tela e no tempo, uma após outra, eletronicamente. A fita de vídeo vista a olho nu é só uma película transparente coberta de emulsão magnética marrom. Para ver todas as imagens e poder imaginar uma seqüência desenhamos em preto e branco, em papel de rascunho, os contornos da paisagem em azul. Contamos o tempo, os minutos, os segundos. Ali, expostas no papel em formas e tempo, à vista assinaladas, as imagens foram compondo os sentidos, tensionando outros.

Havia também o som. O som deveria ser tragado, num sopro, para dentro da imagem. Era preciso ouvi-lo. Pouco a pouco, o exercício de olhar as imagens no papel e na tela foi revelando ruídos, um ritmo, uma música. No mais completo silêncio, ela já se insinuava. Era preciso ouvi-la. Esta música talvez viesse de um instrumento de sopro. Como o vento. Mas qual? Um trecho da música A Lenda, soou com suavidade e firmeza para dentro das imagens. Pudemos, então, reconhecer, nos sons experimentais do grupo Uakti, o movimento identificado no poema - de algo que vai e vem, espraia-se, torna a se erguer para desaparecer de novo, num recomeço incansável. No fim, o silêncio, um "fade-in" e o escuro: 
— a montante a maré apaga tudo — . . .

\section{Na Mesa de Edição}

Discutíamos o assunto como se fôssemos artesãos, cuja matéria bruta já havia sido recolhida, mas necessitasse da moldura e da distorção. Esticar e encolher o tempo da imagem. A mesa de edição era inescrutável em sua inflexível marca científica e tecnológica. E, no entanto, na infinidade dos botões piscantes do aparelho, tentávamos dar forma sonora e visual à tela negra do vídeo que se escondia numa aparente neutralidade.

Tínhamos uma constelação de imagens em azul, imagens que se moviam, mas ainda não falavam. Imagens que mais faziam esquecer - sem que nada fizessem para serem ouvidas. Havia apenas a solidão do esquema de montagem já pronto. O esquema estava pronto, decupado com todos os pedaços de imagens que seriam editados - colados em seqüência. Fomos envolvidos pela maravilhosa onda sonora da música A Lenda. Pensamos a cadência do som que daria voz às imagens aparentemente mudas.

Na mesa de edição, procurávamos traduzir para a linguagem do vídeo uma forma nobre, pausada e metrificada: o poema Juventude, de Mário Faustino. São duas linguagens diferentes, o poema e o vídeo. Então, dessas duas formas que se negam mutuamente e dessa dupla negação surge a imagem entrelaçada em cor, som e ritmo. No vídeo, a linguagem escrita teria que ser desmaterializada, despersonalizada, pois não pretendíamos garantir qualquer vínculo narrativo da mensagens verbais, porém desejávamos formar, plasticamente na tela do vídeo, idéias e sensações, enfim, o lirismo dos versos ocasionais do autor.

As imagens, anteriormente captadas, já consideravam a suspensão espacial e o tempo fugaz dos versos. E, especificamente, no momento da edição é que colávamos sentidos. Palavras, imagens e sons pediam confluência dentro de uma mensagem estética anteriormente elaborada. Era a forma poética das palavras desejando tornarem-se imagens também poéticas. Essa era a idéia central.

Necessitávamos também da síntese relativa dos enquadramentos e a densidade da luz. Nada mais. Estávamos editando, sintetizando signos entranhados na cultura das coisas. Aliás, essa é a fonte da imagem: o concreto e a realidade são o impulso para criar a edição.

Então, na mesa de edição, colamos as aparentes fotografias em movimento. A série de fotografias foram se encadeando em uma única seqüência, em movimento: o vídeo. Os pequenos trechos de imagens que, antes, pareciam unidades imóveis, semelhante àquilo que ocorre nos filmes, agora, eram imagens imbuídas de movimento e duração. " $A$ imagem 
estende-se por um determinado intervalo de tempo e algo pode mover-se de dentro para fora do campo de visão ou vice-versa. Essa é uma possibilidade específica da imagem cinematográfica, graças à sua duração. "5 O Discurso Cinematográfico.
Dentro dos enquadramentos escolhidos, delimitávamos mostrar apenas algumas coisas identificáveis. O corpo no jogo claro e escuro $\mathrm{O}$ contraste das luzes em seqüências, tal como as seqüências de pensamentos que temos sobre alguma coisa real.

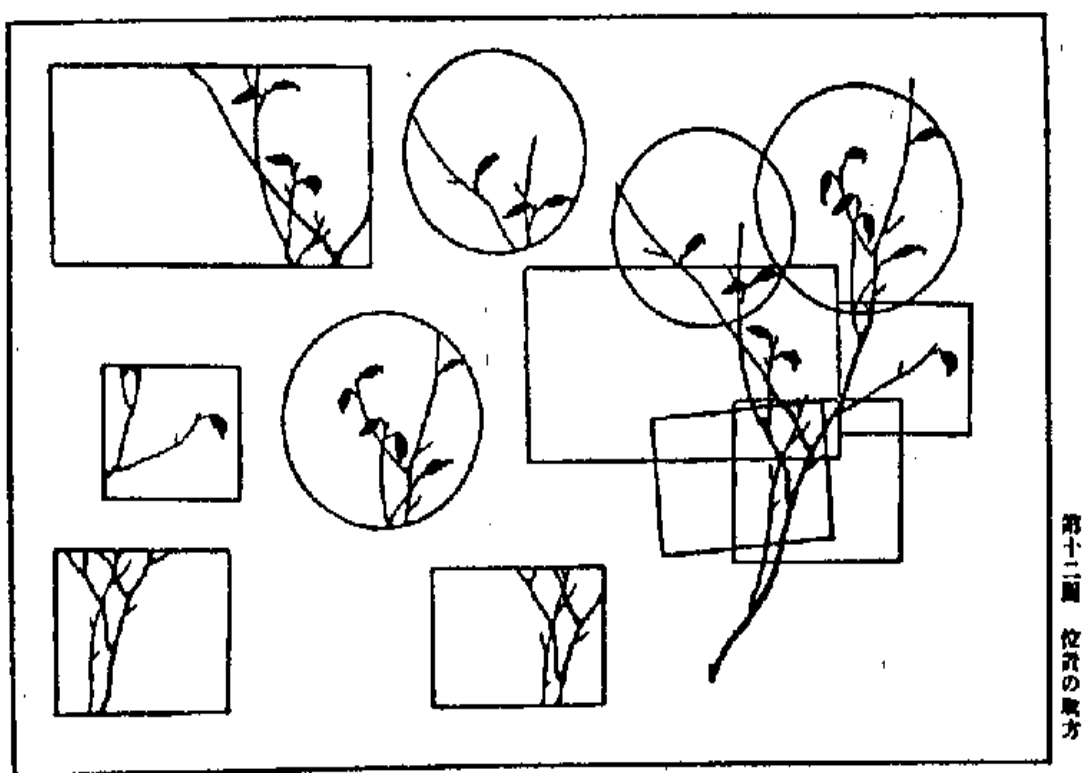

${ }^{5}$ Ismail Xavier, “A Opacidade e a Transparência”, em O Discurso Cinematográfico, RJ, Paz e Terra, 1984, p.14. 
No momento da edição, vimos como aqueles pedaços de imagens em azul se encaixariam na forma do vídeopoema, em imagens e sons dos quais emergiriam conteúdo e significação. Compreender e ver o avesso das palavras e desse movimento retirar o essencial. Transformações. Combinações. Justaposições. Agregações. Mosaicos em movimento sonorizados. Junções sonorizadas. Detalhes parciais, em justaposição, participando cada um da imagem total, de onde desprega-se o tema. ${ }^{6}$

Nesse tecido de imagens, sons e palavras, como num livro em que se lê na capa, na contracapa, na folha de rosto, informações sobre sua produção, no video; os créditos sobem, no final, notificando o espectador sobre as parcerias que envolveram sua realização - é o que chamamos de ficha técnica. Ler o vídeo é também ler os créditos finais, os quais participam de sua significação.

Concluído o trabalho, o vídeo conta $4 \mathrm{~m} 12 \mathrm{~s}$ de duração e foi batizado com o nome Paisagem em Azul.

\footnotetext{
${ }^{6}$ A gravura encaixada neste paragráfo foi retirada do livro de Sergei Eisenstein, A Forma do Filme, RJ, Jorge Zahar Editor Ltda, 1990, e encontra-se no cap. "Fora de Quadro". Trata-se de um exemplo dado pelo autor para falar, através do método japonês de ensino de desenho, de enquadramento, plano e montagem.
} 